\title{
Characterization of the Deoxycytidine Kinase Promoter in Human Lymphoblast Cell Lines
}

\author{
Everett H. Chen, ${ }^{\star}$ Earnest E. Johnson II, ${ }^{\star}$ Steven M. Vetter, ${ }^{\star}$ and Beverly S. Mitchell** \\ *Department of Pharmacology and ${ }^{\ddagger}$ Department of Medicine, University of North Carolina, Chapel Hill, North Carolina 27599
}

\begin{abstract}
Deoxycytidine kinase (dCK) phosphorylates 2'-deoxycytidine, as well as the purine deoxyribonucleosides and a number of nucleoside analogues that are important in the chemotherapy of leukemias. The enzyme is highly expressed in the thymus relative to other tissues and may play an important role in the $\mathbf{T}$ cell depletion associated with adenosine deaminase and purine nucleoside phosphorylase deficiencies. To characterize the dCK promoter region and to determine whether it mediates higher levels of gene expression in $\mathbf{T}$ lymphoblasts, we have analyzed a 700-bp genomic fragment encompassing 548 bp of $5^{\prime}$ flanking region for functional activity and for transcription factor binding using $T$ and $B$ lymphoblast cell lines and nuclear extracts. The regions of the promoter that were defined as important to its function include a 5'GC box, an E box, a 3'GC box, and an E2F site. The transcription factor Sp1 binds to both GC boxes, activating at the $5^{\prime}$ site but repressing at the $3^{\prime}$ site. MLTF/ USF activates transcription through the $E$ box, whereas $E 2 F$ activates through the E2F site, but binds weakly to this site in vitro and does not appear to mediate cell cycle-specific expression of $\mathrm{dCK}$ in vivo. No significant differences in promoter activity or transcription factor binding were observed between Jurkat $\mathbf{T}$ and Raji $B$ lymphoblasts. The promoter of the dCK gene is thus regulated by a number of ubiquitously expressed transcription factors. DCK expression in cultured lymphoblast cell lines is not solely a function of the $\mathbf{T}$ or $B$ lineage derivation. (J. Clin. Invest. 1995. 95:1660-1668.) Key words: adenosine deaminase $\cdot$ purine nucleoside phosphorylase $\bullet$ cell cycle $\bullet$ transcription factor $\bullet$ gene expression - nucleoside
\end{abstract}

\section{Introduction}

Deoxycytidine kinase (NTP:deoxycytidine 5'-phosphotransferase, EC 2.7.1.74; $\mathrm{dCK})^{1}$ catalyzes the phosphorylation of $2^{\prime}$ -

Address correspondence to Beverly S. Mitchell, M.D., 1106 FLOB CB\#7365, University of North Carolina, Chapel Hill, NC 27599-7365. Tel.: 919-966-4330; Fax: 919-966-5640.

Received for publication 22 September 1994 and in revised form 10 October 1994.

1. Abbreviations used in this paper: ADA, adenosine deaminase; bHLH, basic helix-loop-helix; CdA, 2-chlorodeoxyadenosine; dCK, deoxycytidine kinase; DHFR, dihydrofolate reductase; SSP, stage selector protein; TK, thymidine kinase; CAT, chloramphenicol acetyltransferase; CMV, cytomegalovirus; RSV, Rous sarcoma virus.

J. Clin. Invest.

(C) The American Society for Clinical Investigation, Inc.

0021-9738/95/04/1660/09 \$2.00

Volume 95, April 1995, 1660-1668 deoxycytidine to its $5^{\prime}$-monophosphate and, despite a much higher $K_{\mathrm{m}}$ for the purine deoxyribonucleosides, also plays a major role in phosphorylating $2^{\prime}$-deoxyadenosine and 2 '-deoxyguanosine to their corresponding monophosphates (1-4). $\mathrm{dCK}$ is also central in the activation of anticancer and antiviral agents such as cytosine arabinoside, fludarabine, $2^{\prime}, 3^{\prime}$ '-dideoxycytidine, and 2-chlorodeoxyadenosine (CdA) (5-9). Cell lines lacking dCK activity are resistant to these nucleoside analogues (10), whereas increased dCK activity has been associated with increased sensitivity to these agents (11).

dCK also may play an important role in the pathogenesis of the immunodeficiency syndromes associated with deficiencies of the purine catabolic enzymes adenosine deaminase (ADA) and purine nucleoside phosphorylase (12). The preferential cytotoxicity of the ADA substrate, $2^{\prime}$-deoxyadenosine, and the purine nucleoside phosphorylase substrate, 2'-deoxyguanosine, for human thymocytes has been thought to account for the $\mathrm{T}$ cell depletion in these disorders. Cytotoxicity has been attributed to the ability of thymocytes and human $T$ lymphoblasts to accumulate the corresponding 2'-deoxyribonucleoside triphosphates from these substrates, resulting in inhibition of DNA synthesis. Deoxyribonucleotide accumulation in turn has been felt to result from the relatively high levels of $\mathrm{dCK}$ and the low levels of $5^{\prime}$-nucleotidase in these cells. Several studies have demonstrated higher levels of dCK activity (1315) and mRNA (16) in human thymocytes and T lymphoblasts than in other tissues, including EBV-immortalized B lymphoblasts, although normal peripheral blood $\mathrm{T}$ and $\mathrm{B}$ cells appear to contain similar amounts of dCK activity and immunoreactive protein (17).

To understand the molecular basis for tissue-specific regulation of dCK activity in normal and neoplastic human cells, we have cloned the dCK gene and identified its promoter (18). The 5' region of the gene is highly GC rich and lacks TATA or CAAT boxes. It does have an E2F site similar to those found in the promoters of dihydrofolate reductase (DHFR), thymidine kinase (TK), c-myc, and other genes important for the initiation of DNA synthesis $(19,20)$. Preliminary transfection experiments into transformed human $\mathrm{T}$ and $\mathrm{B}$ lymphoblast cell lines revealed significantly higher levels of expression of this promoter in T lymphoblasts. Since the regulation of expression of this gene may directly relate to the chemosensitivity of neoplastic cells to certain nucleoside analogs, we have further defined the mechanisms responsible for its regulation in cultured lymphoblast cell lines.

\section{Methods}

Deletion mutants. A 700-bp HindIII fragment spanning the promoter, first exon, and $61 \mathrm{bp}$ of the first intron was cloned into pCAT-Basic (Promega, Madison, WI) to yield pCAT-Basic 700 (see Fig. 2). Digestion of this construct with SmaI resulted in the removal of $183 \mathrm{bp}$ of $5^{\prime}$ sequence (pCAT-Basic 517). Removal of the first intron segment, first exon, and most of the $5^{\prime}$ untranslated region from pCAT-Basic 517 with SacI produced pCAT-Basic 244 . The 244-bp promoter was 
cloned into pUC CAT to take advantage of the SacI and SmaI sites in the multiple cloning site. Deletions were made from the $5^{\prime}$ end after digestion with SacI and SmaI to create exonuclease-resistant and susceptible ends, respectively, using an Exo III/Mung bean nuclease deletion kit from Stratagene (La Jolla, CA). All deletion mutant plasmids were prepared using Qiagen columns (Chatsworth, CA) and sequenced by the dideoxy chain termination method (USB, Cleveland, $\mathrm{OH}$ ).

Transfections. Jurkat $\mathrm{T}$ lymphoblasts and Raji B lymphoblasts were grown in RPMI and 10\% FCS. Cells were harvested during exponential growth, washed in serum-free medium, and resuspended at $10^{7}$ cells per $400 \mu \mathrm{l}$ of RPMI. CAT plasmids $(30 \mu \mathrm{g})$ and cytomegalovirus (CMV)-lacZ or $\beta$-actin-lacZ plasmids (courtesy of Lorraine Gudas, Cornell University, NY) $(10-30 \mu \mathrm{g})$ were resuspended in $100 \mu \mathrm{l}$ of PBS and mixed with the cells. Electroporation was performed with a Gene Pulser (Bio-Rad Laboratories, Richmond, CA) with 0.4-cm cuvettes at $250 \mathrm{~V}, 960 \mu \mathrm{F}$. Cells were harvested after $48 \mathrm{~h}$, and extracts were prepared by three freeze-thaw cycles and removal of insoluble debris by centrifugation. For chloramphenicol acetyltransferase (CAT) assays, 5-50- $\mu$ l aliquots of heated cell extracts (21) were assayed with $0.1 \mu \mathrm{Ci}$ of $\left[{ }^{14} \mathrm{C}\right]$ chloramphenicol and $25 \mu \mathrm{g}$ of $n$-butyryl CoA in 125 $\mu \mathrm{l}$. Reactions were stopped with xylenes, and the reaction products were extracted and counted (22). $\beta$-Galactosidase activity was measured in unheated extracts using chlorophenol red $\beta$-D-galactopyranoside as a substrate (23).

Nuclear extracts. Extracts were made from exponentially growing Jurkat and Raji cells by the method of Dignam et al. (24) with modifications as described by Blake et al. (25). Cells were homogenized in buffer A ( $10 \mathrm{mM}$ Hepes, $\mathrm{pH} 7.9,0.75 \mathrm{mM}$ spermidine, $0.15 \mathrm{mM}$ spermine, 0.1 mM EDTA, $0.1 \mathrm{mM}$ EGTA, $10 \mathrm{mM} \mathrm{KCl,} 1 \mathrm{mM}$ DTT, $1 \mathrm{mM}$ PMSF), and nuclei were sedimented by centrifugation at $30,000 \mathrm{~g}$ for $30 \mathrm{~s}$. Nuclear factors were then extracted in buffer C $(20 \mathrm{mM}$ Hepes, $\mathrm{pH} 7.9$, $0.2 \mathrm{mM}$ EDTA, $0.2 \mathrm{mM}$ EGTA, $2 \mathrm{mM}$ DTT, $20 \%$ glycerol, $0.15 \mathrm{mM}$ spermine, $0.75 \mathrm{mM}$ spermidine, $1 \mathrm{mM}$ PMSF, $0.4 \mathrm{M} \mathrm{NaCl}$ ). The extract was subjected to centrifugation for $45 \mathrm{~min}$ at $300,000 \mathrm{~g}$, followed by dialysis in modified buffer $\mathrm{D}$ ( $20 \mathrm{mM}$ Hepes, $\mathrm{pH} 7.9,20 \%$ glycerol, $100 \mathrm{mM} \mathrm{KCl}, 0.2 \mathrm{mM}$ EDTA, $0.2 \mathrm{mM}$ EGTA, $2 \mathrm{mM}$ DTT, $1 \mathrm{mM}$ PMSF, $12.5 \mathrm{mM} \mathrm{MgCl}_{2}$ ). The extracts were aliquoted and stored at $-70^{\circ} \mathrm{C}$.

DNase I footprinting. Three probes were prepared to span the region from -450 to +151 (relative to the translation start site) of the dCK promoter. The first probe was prepared by digesting the 700-bp promoter with PstI, end labeling with Klenow (taking advantage of its $3^{\prime} \rightarrow 5^{\prime}$ exonuclease activity), and digesting with BglI, yielding a 254-bp probe spanning -450 to -197 . A second probe was prepared by digesting the promoter with NarI, incubating with calf intestinal alkaline phosphatase, and labeling the ends with T4 polynucleotide kinase or Klenow. This labeled DNA was then cut with MaeIII, yielding a 217-bp probe spanning -299 to -83 . A third probe was prepared by digesting the promoter with HindIII, labeling with Klenow, and digesting with Cfr10I. This last 291-bp probe spanned the region between -140 and +151 . Probes were electrophoresed on nondenaturing polyacrylamide gels and eluted by the "crush and soak" method (26). DNase footprinting was performed according to Blake et al. (25). 5-10 ng of end-labeled DNA was incubated with nuclear extract in the presence of $15 \mu \mathrm{g}$ of poly (dI$\mathrm{dC}$ ) in a $120-\mu \mathrm{l}$ volume containing $6.1 \%$ glycerol, $0.07 \mathrm{mM}$ EDTA $0.07 \mathrm{mM}$ EGTA, 7.2 mM Hepes, $\mathrm{pH} 7.9,39 \mathrm{mM} \mathrm{KCl}, 7.5 \mathrm{mM} \mathrm{MgCl}_{2}$, and $0.7 \mathrm{mM}$ DTT. The binding reaction mixtures were incubated on ice (for kinase-labeled probes) or at room temperature for $30 \mathrm{~min}$. $\mathrm{CaCl}_{2}$ ( $2 \mathrm{mM}$ final concentration) was added, and protein-DNA complexes were digested with DNase I (Worthington Enzymes, Freehold, NJ) for 4 min at room temperature. Purified Spl was purchased from Promega, and footprinting reactions were done according to the Promega protocol Digestions were stopped by adding $2 \mathrm{vol}$ of a mix containing $100 \mathrm{mM}$ Tris, $\mathrm{pH} 8,20 \mathrm{mM}$ EDTA, $0.1 \%$ SDS, $100 \mu \mathrm{g} / \mathrm{ml}$ proteinase $\mathrm{K}$, and $100 \mu \mathrm{g} / \mathrm{ml}$ glycogen. After incubation at $37^{\circ} \mathrm{C}$ for $20 \mathrm{~min}$, the samples were extracted with phenol-chloroform and precipitated with ethanol. Samples were resuspended in formamide loading dye and run on $6 \%$ sequencing gels.

Site-directed mutagenesis. Mutagenesis of the promoter was accom- plished by the method of Kunkel et al. (27) with the $3^{\prime} \mathrm{GC}-\mathrm{M}_{1}$ oligonucleotide, or by recombinant PCR (28). Sense-strand mutagenic primers are shown below, with the consensus transcription factor-binding sites underlined and the mutated bases shown in lowercase:

5'GC-M ACACGCGCGGCCCaaaCCCGGCCTT

E box-M CCCGGCCTTCACGaCACCTGGCGTGCG

$3^{\prime}$ 'GC-M $M_{1}$ GCTTGAGGAGaatacGGCCGCCCC

3 'GC-M ${ }_{3}$ GCGGCTTGAGGAGGaatctagaaaCCCGCAGGCCCG

\section{E2F-M CTCCGCGL ACCAAAGTCAAA}

Oligonucleotide substitutions were designed as reported previously (25, 29-31), or were shown not to bind the relevant transcription factor by gel-shift assays. 7-Deaza-dGTP (1:1 with dGTP) was used to amplify the GC-rich promoter, and Pfu DNA polymerase (Stratagene) was used to maximize fidelity of DNA synthesis. Promoter fragments containing the designated substitutions were cloned into pCAT-Basic at the SalI site. All plasmids were prepared using Qiagen columns and sequenced.

Gel-shift assays. The sequences of the wild-type sense oligonucleotides are shown below, with the consensus transcription factor-binding sites underlined:

$5^{\prime}$ GC and E boxes CCACACGCGCGGCCCCGCCCCGGCCTTCAC-

\section{GTGACCTGCGT}

AdMLP AGGTGTAGGCCACGTGACCGGGTGT

3 'GC box

$\mathrm{E} 2 \mathrm{~F}-\mathrm{dCK}$ GCGGCTTGAGGAGGGCGGGGCCGCCCCGCAGG

E2F-DHFR CTCCGCGCGCCAAAGTCAAACCCCGACA

Oligonucleotides were annealed, end labeled with Klenow, and purified on NENSORB columns (Du Pont NEN, Boston, MA). For most experiments, $0.2 \mathrm{ng}$ of probe was incubated with $4-10 \mu \mathrm{g}$ of nuclear extract in $12 \mathrm{mM}$ Hepes, $\mathrm{pH} 7.9,60 \mathrm{mM} \mathrm{KCl}, 0.6 \mathrm{mM}$ DTT, $1 \mathrm{mM}$ EDTA, $12 \%$ glycerol, $1 \mathrm{mM} \mathrm{MgCl}$, and $2 \mu \mathrm{g}$ of poly(dI-dC) in $20 \mu \mathrm{l} \mathrm{(32).}$ For E2F gel shifts, the incubation buffer consisted of $20 \mathrm{mM}$ Hepes, $\mathrm{pH} 7.8,1 \mathrm{mM} \mathrm{MgCl}_{2}, 0.1 \mathrm{mM}$ EDTA, $40 \mathrm{mM} \mathrm{KCl}, 0.5 \mathrm{mM}$ DTT, $1.5 \% \mathrm{NP}-40,1 \%$ Ficoll, $2 \mu \mathrm{g}$ of salmon sperm DNA, and $60 \mu \mathrm{g}$ of BSA (33). Incubations were allowed to go for $20 \mathrm{~min}$ at room temperature. If competitor oligonucleotides were used, they were allowed to preincubate on ice for $10 \mathrm{~min}$ before addition of the probe. With antibodies, the preincubation time was $2-4 \mathrm{~h}$ on ice. With purified Spl, $10 \mu \mathrm{g}$ of BSA was included in the incubation. Anti-Spl antibody was purchased from Santa Cruz Biotechnology (Santa Cruz, CA), and anti-USF was provided by Robert Roeder (The Rockefeller University, New York). Binding reactions were resolved on 4\% (30:1 acrylamide/bis) nondenaturing Tris-glycine- $2.5 \%$ glycerol or $0.5 \times$ Tris-borate-EDTA minigels. Gels were run at $100 \mathrm{~V}$, dried, and autoradiographed.

Nuclear run-on assays. Single-stranded probes for portions of exon 1 ( 322 bases), intron 2 (400 bases), and exon 6 (422 bases) were prepared by cloning into $\mathrm{M} 13 \mathrm{mp} 18$ or $\mathrm{M} 13 \mathrm{mp} 19$. All other probes were prepared from cDNAs in double-stranded plasmids. Cells $\left(5 \times 10^{7}\right)$ in exponential growth were harvested, washed in PBS, resuspension buffer ( $10 \mathrm{mM}$ Tris, $\mathrm{pH} 7.4,10 \mathrm{mM} \mathrm{NaCl}, 5 \mathrm{mM} \mathrm{MgCl}_{2}$ ), and resuspension buffer $+0.5 \%$ NP- -40 . Nuclei were then resuspended in $210 \mu$ l of nuclear freezing buffer ( $50 \mathrm{mM}$ Tris, $\mathrm{pH} 8.3,40 \%$ glycerol, $5 \mathrm{mM} \mathrm{MgCl} 2,0.1$ mM EDTA). $60 \mu$ of $5 \times$ run-on buffer $(25 \mathrm{mM}$ Tris, $\mathrm{pH} 8.0,12.5$ $\mathrm{mM} \mathrm{MgCl}, 750 \mathrm{mM} \mathrm{KCl}, 1.25 \mathrm{mM}$ each of ATP, CTP, and GTP) and $30 \mu \mathrm{l}(300 \mu \mathrm{Ci})$ of $\left[\alpha-{ }^{32} \mathrm{P}\right] \mathrm{UTP}$ were added, and labeling was allowed to proceed for $30 \mathrm{~min}$ at $30^{\circ} \mathrm{C}$, with intermittent mixing. Nascent RNA was isolated with Tri Reagent (Molecular Research Center, Cincinnati, $\mathrm{OH}$ ) according to Srivastava et al. (34). RNA was cleaved for $10 \mathrm{~min}$ at $4^{\circ} \mathrm{C}$ with $0.2 \mathrm{M} \mathrm{NaOH}$, neutralized with Hepes buffer $(0.48 \mathrm{M})$, and precipitated with ethanol. Blots were prepared by loading $5 \mu \mathrm{g}$ of alkaline-denatured plasmid directly onto a Zeta-Probe membrane (Bio-Rad Laboratories), using a slot-blot apparatus. Equivalent amounts of labeled RNA were hybridized to the blots in $0.25 \mathrm{M} \mathrm{NaH}_{2} \mathrm{PO}_{4}, \mathrm{pH} 7.2$, $7 \%$ SDS for $2 \mathrm{~d}$ at $65^{\circ} \mathrm{C}$. Blots were washed with $10 \mu \mathrm{g} / \mathrm{ml}$ RNase A in $2 \times \mathrm{SSC}$ for $30 \mathrm{~min}$ at $37^{\circ} \mathrm{C}$. Final washes were in $0.1 \times \mathrm{SSC}, 0.1 \%$ SDS at $65^{\circ} \mathrm{C}$. After autoradiography, blots were placed in a phosphorimager screen for quantitation.

Northern blots. RNA was prepared with Tri reagent and dissolved in Formazol (Molecular Research Center). In mRNA stability experi- 


\begin{abstract}
-548 AAGCTTTAAGTCTATCCAGTTCTGTCCAGACGCGTCTGTTCATCTCCAACA GGCCCACTAGAGAGGCGGGTTTTCCAAAGCCTGCACGGCCCACTGCAGGT

-447 GACGCCCTCTGCCCTCCAGCGCCCTCAGGCCTCTGGGGTCCACCCTTCCT

Sma I

CCCCACCCGACTCCGGAACCTCTTCCGCGCTG/CCCGGGCGCCTGGCTGCT

S'GC box E box

-347 TGGGGTAGAGGCCTTCCGCCACACGCGCGGCCCCGCCCCGGCCTTCACGT

GACCTG/GCGTGCGGAGCGCGCAGCGGGAACCCGCGCTGGAGGCGGGCGAG

3 ' GC box

GGCCGAGGGGCAGCTAGG/GAGCGCGGCTTGAGGAGGGCGGGGCCGCCCCG

E2E

CAGGCCCGCCAGT / GTCCTCAGCTGCCTCCGCGCGCCAAAGTCAAA/CCCCG

Sac I

-147 ACACCCGCCGGCGGGCCGGTGAGCTC/ACTAGCTGACCCGGCAGGTCAGGA

TCTGGCTTAGCGGCGCCGCGAGCTCCAGTGCGCGCACCCGTGGCCGCCTC
\end{abstract}

$+1$

CCAGCCCTCTTTGCCGGACGAGCTCTGGGCCGCCACAAGACTAAGGAATG

GCCACCCCGCCCAAGAGAAGCTGCCCGTCTTTCTCAGCCAGCTCTGAGGG

$+54$

AATGTGGGACGCAAGGCTGGGGTGTCGCGGCAGTGGCTGAAGCTT

Figure 1. Sequence of the human dCK gene promoter, from Song et al. (18). Boundaries of the deletion mutants ( $/$ ) and DNase I-protected regions (italics) are shown. Consensus sites for transcription factor binding are underlined. The arrow indicates the putative transcription start site, and +1 refers to the $A$ of the ATG initiator codon. Bold letters indicate additional bases in this revised sequence. Smaller letters indicate intron 1 sequence. ments, actinomycin D ( $5 \mu \mathrm{g} / \mathrm{ml})$ was added to the cells. Total RNA ( $10 \mu \mathrm{g}$ per lane) was fractionated in denaturing formaldehyde-agarose gels and then transferred to nylon membranes. A truncated version of the full-length dCK cDNA (clone G) (16) was labeled by the random primer method (35), and hybridization was performed in High Efficiency Hybridization Buffer with formamide (Molecular Research Center) overnight at $42^{\circ} \mathrm{C}$. Final washes, autoradiography, and quantitation were performed as previously described. 28S rRNA oligonucleotide was labeled with $\left[\gamma-{ }^{32} \mathrm{P}\right]$ ATP and T4 polynucleotide kinase. The blot stripped of dCK probe was hybridized overnight at $37^{\circ} \mathrm{C}$ and washed several times with $5 \times \mathrm{SSPE}, 0.1 \%$ SDS at $50^{\circ} \mathrm{C}$

$d C K$ activity assay. The assay was performed using CdA $(0.5 \mu \mathrm{M}$ $\left[8-{ }^{3} \mathrm{H}\right] \mathrm{CdA}, 49.5 \mu \mathrm{M}$ unlabeled $\left.\mathrm{CdA}\right)$ as a substrate $(15) \cdot\left[8-{ }^{3} \mathrm{H}\right] \mathrm{CdA}$ was purchased from Moravek Biochemicals (Brea, CA), and unlabeled CdA was obtained from Ortho Biotech (Raritan, NJ). Linearity was maintained with up to $30 \mu \mathrm{g}$ of protein per $50 \mu \mathrm{l}$ for at least $1 \mathrm{~h}$.

\section{Results}

We demonstrated previously that a 700-bp HindIII fragment from the dCK gene possesses promoter activity upon transfection into human lymphoblast cell lines, with 12-19-fold higher activity in Jurkat T lymphoblasts than in Raji B lymphoblasts after normalizing for transfection efficiency with cotransfection of CMV - or Rous sarcoma virus (RSV)-lacZ (18). Fig. 1 shows the sequence of this fragment, corrected with the addition of 3 bases at $-292,-144$, and -140 . To delineate basal elements and to explore possible cell-specific elements in the promoter, we analyzed a series of deletion mutants for promoter activity (Fig. 2). Deletion of $183 \mathrm{bp}$ of $5^{\prime}$ sequence (pCATBasic 517) increased promoter activity by two- to threefold. Deletion of $273 \mathrm{bp}$ from the 3' end removed much of the 5' untranslated sequence, the first exon, and the first intron segment (pCAT-Basic 244). This fragment produced $20-25 \%$ of the CAT activity of pCAT-Basic 517, despite the removal of the competing translation start site from the dCK gene. When serial exonuclease deletions were made from the $5^{\prime}$ end of the 244-bp promoter, a $50-70 \%$ drop in CAT activity occurred after the removal of $74 \mathrm{bp}$. The deleted segment contained a GC-rich consensus Sp1 site (5'GC box) and an E box. Further deletions did not cause further decreases in promoter activity.

The CAT activity profiles of the deletion mutants in Jurkat as compared with Raji cells were identical when portrayed as a percentage of 244-bp promoter activity in their respective cells. However, the CAT/ $\beta$-galactosidase ratios in Jurkat cells were 100-1,000-fold higher than those in Raji cells. This difference could not be accounted for by a difference in transfection efficiency, since $\beta$-galactosidase activities from cotransfected constructs driven by CMV, RSV, or $\beta$-actin promoters were always higher in Raji cells. Since the background CAT activities from a series of CAT vectors (pUC CAT, pCAT-Basic, pBS CAT) were always higher in Jurkat cells, we speculate that a common vector element outside the promoter mediates increased expression in these cells. These data support the concept that the regulation of the dCK promoter does not differ in these model $\mathrm{T}$ and $\mathrm{B}$ lymphoblast cell lines.

We used DNase I footprinting analysis to identify sites of transcription factor binding within the dCK promoter. Three probes were used to span the promoter from -450 to +151 . The first probe, extending from -450 to -197 , demonstrated an extended footprint from -327 to -291 (Fig. $3 \mathrm{~A}$ ), the region that encompasses the 5' GC box and the $\mathrm{E}$ box. A second protected region was observed from -221 to -197 , corresponding to the $3^{\prime} \mathrm{GC}$ box. This footprint was also detected using the probe from -299 to -83 (Fig. $3 \mathrm{~B}$ ). The region encompassing the E2F site was difficult to evaluate since it was resistant to DNase I digestion in the absence of nuclear extract, although 


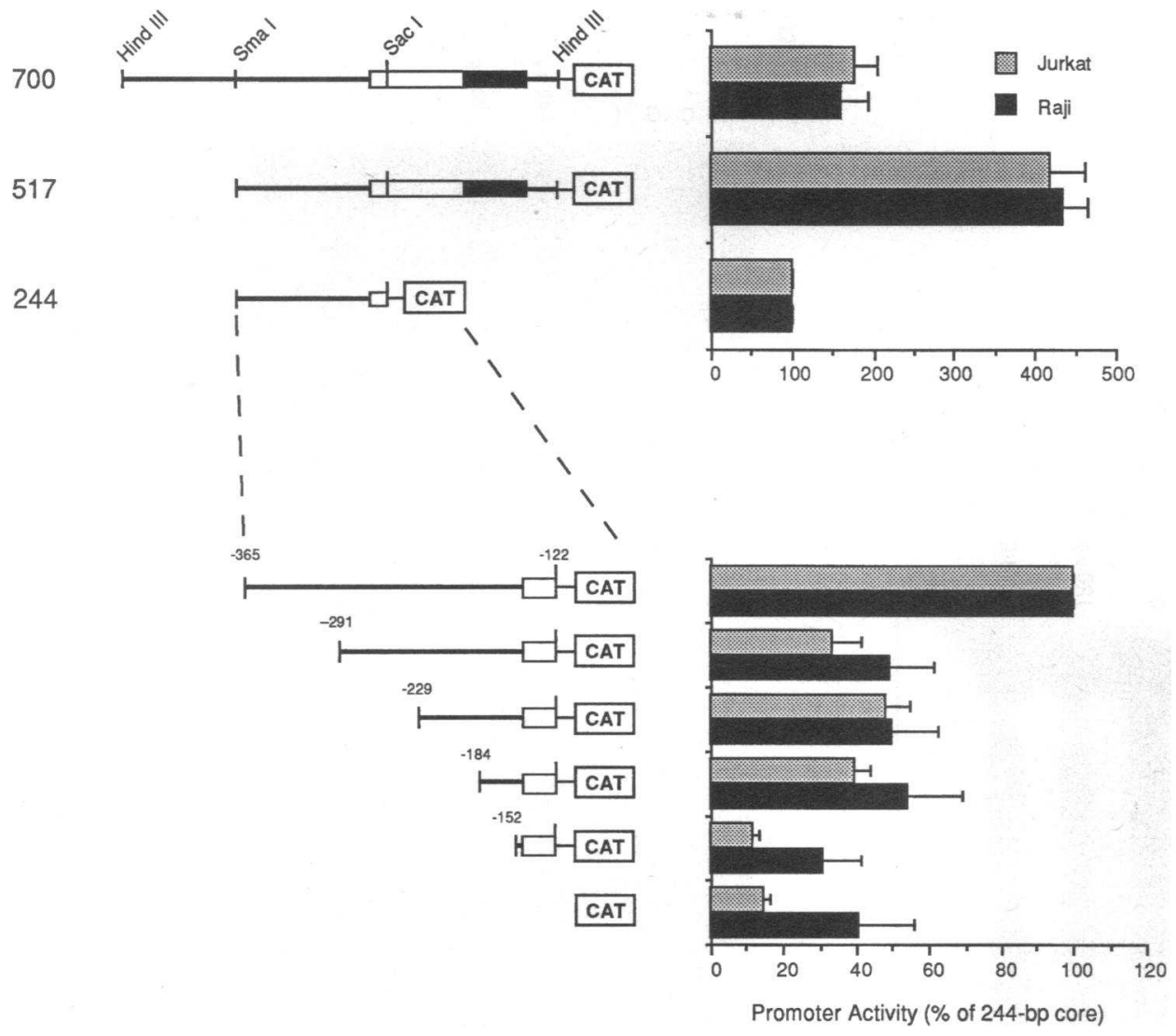

Figure 2. Transfection of promoter constructs into Jurkat and Raji cells. Deletions were made by restriction endonuclease or exonuclease III digestion. Cells were transfected with CAT and $l a c Z$ plasmids by electroporation and harvested $2 \mathrm{~d}$ later. Enzyme assays were performed as described in Methods. CAT activities were normalized to $\beta$-galactosidase activities to control for transfection efficiency and are shown relative to that of the 244-bp promoter in each cell type. In the schematic diagram of the constructs, open boxes represent the $5^{\prime}$ untranslated region and closed boxes represent the coding region of exon 1. Bases are numbered relative to the translation start site. Bars, representing mean $\pm S D$, are the results of two independent experiments done in duplicate. hypersensitive sites were clearly observed on either side of the E2F site with DNase I digestion (Fig. 3 B). Similar resistance to DNase I cleavage has also been observed at the E2F site of the hamster DHFR gene (29). No sites of protection from or hypersensitivity to DNase I digestion were detected in the region from -140 to +151 (data not shown). DNase I footprints were identical using either Jurkat or Raji nuclear extracts.

The functional significance of the protected regions was evaluated by in vitro mutagenesis and transfection analysis. Four regions were independently mutated: the $5^{\prime} \mathrm{GC}$ box, $\mathrm{E}$ box, 3'GC box, and E2F site. As shown in Fig. 4, mutation of the $5^{\prime} \mathrm{GC}$ box reduced CAT activity by $50-70 \%$ relative to the wild-type 244-bp promoter. Mutation of the $\mathrm{E}$ box decreased CAT activity by $50 \%$. In our $\mathrm{E}$ box mutant, we mutated CACGTG to CACGAC to prevent basic helix-loop-helix (bHLH) transcription factors from binding (31). This mutation inadvertently created a new E box, CACGACACCTG, but the consistent reduction in CAT activity strongly suggests that it cannot substitute for the native site. A 5-bp substitution of the $3^{\prime} \mathrm{GC}$ box $\left(\mathrm{M}_{1}\right)$ caused an unexpected increase in CAT expression that was more modest in Jurkat cells ( $150 \%$ of wild type) than in Raji cells ( $250 \%$ of wild type). To confirm this result, we changed and extended the mutation at this site by replacing 10 bases ( $3^{\prime} \mathrm{GC}-\mathrm{M}_{3}$ ). CAT activity remained consistently above that of the 244-bp native promoter (200-270\%). Mutation at the E2F site reduced promoter activity by $30-60 \%$, suggesting a functional role for this region.

Gel-shift analysis was performed to identify the specific transcription factor(s) binding to these regions. The 5'GC and $E$ boxes were included in one oligonucleotide probe. Incubation of this probe with either Jurkat or Raji nuclear extracts yielded three bands (Fig. $5 \mathrm{~A}$ ). The top and bottom bands were competed by an unlabeled 22-bp oligonucleotide with a perfect Sp1 consensus sequence, a result consistent with the known doublet pattern of Sp1 in gel-shift assays (30). The middle band was competed by an oligonucleotide containing the CACGTG sequence from the adenovirus major late promoter. Although the 5'GC box and the E box formed one extended footprint, these gel-shift results suggest that Sp1 and USF do not bind cooperatively; no conclusions can be made about competitive interactions. Antibody to $\mathrm{Sp} 1$ supershifted the $\mathrm{Sp} 1$ complexes, whereas anti-USF antibody prevented protein binding to the E box. Spl also bound to the $3^{\prime} \mathrm{GC}$ box (Fig. $5 \mathrm{~B}$ ) with the expected competition and antibody supershift patterns. When the E2F site of the dCK promoter was used in a gel-shift assay, no shifted bands were apparent (data not shown). Using the same conditions, a 29-bp dyad E2F site from the hamster DHFR promoter did shift (Fig. $5 \mathrm{C}$ ). The dCK E2F site was able to compete for binding with the DHFR E2F probe, but was not as strong a competitor as the DHFR E2F site oligonucleotide. Identical results were obtained with a second dCK E2F competitor that had $14 \mathrm{bp}$ instead of $5 \mathrm{bp}$ of 5' sequence to control for the presence of a nonconsensus dyad site. No differences in protein binding were observed with any of the probes between Jurkat and Raji nuclear extracts.

Since no significant differences were observed in dCK promoter activity or protein binding between Jurkat and Raji cells, we performed nuclear run-on transcription assays to measure directly the relative levels of dCK transcription in these cells (Fig. $6 A$ ). Exon 1 transcription was easily detected with a single-stranded probe to the sense strand. No transcription was detected through intron 2 and exon 6, suggesting increased RNA 
B

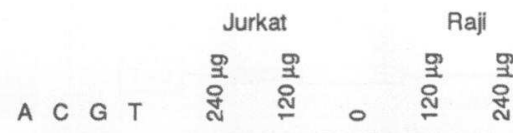

A
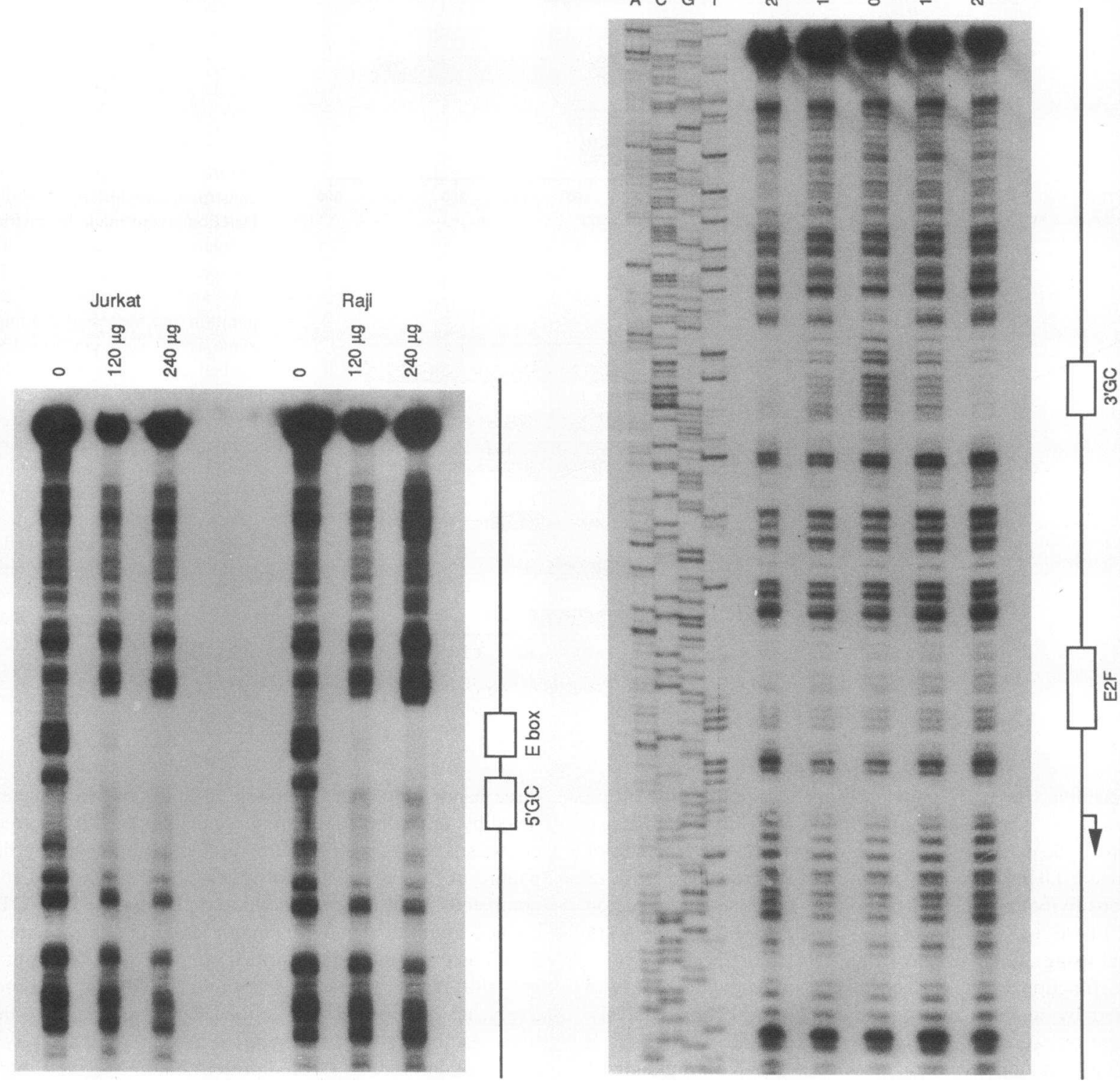

Figure 3. DNase I footprint analysis of the dCK promoter. DNA probes from -450 to $-197(A)$ and -299 to $-83(B)$ were end labeled, purified, and incubated with the indicated amount of Jurkat or Raji nuclear extract before DNase I digestion. Cleavage products were separated on a $6 \%$ denaturing acrylamide gel along with the corresponding dideoxy sequencing reaction. Boxes indicate consensus sequences for transcription factorbinding sites, and the arrow indicates the putative transcription start site.

polymerase density at exon 1 and/or transcription arrest/attenuation between exon 1 and intron 2 . Opposite strand transcription was undetectable using exon 1 , intron 2 , and exon 6 probes (data not shown). This result was reproducible using either [ $\alpha$ $\left.{ }^{32} \mathrm{P}\right] \mathrm{UTP}$ or $\left[\alpha-{ }^{32} \mathrm{P}\right] \mathrm{CTP}$, with $\mathrm{NaOH}$ cleavage of transcripts before hybridization and RNase $\mathrm{A}$ in the wash for maximum specificity. Unexpectedly, exon 1 transcription was higher in Raji than in Jurkat cells. Controls included $\beta$-actin and ADA, which is transcribed at high levels in T lymphoblasts (36). Northern blots of dCK steady-state mRNA levels (Fig. $6 B$ ) and enzyme activities (Fig. $6 C$ ) correlated with the exon 1 transcription data. Measurements of the dCK mRNA half-life after actinomycin $\mathrm{D}$ treatment demonstrated equivalent values of 2-4 $\mathrm{h}$ in Jurkat and Raji cells (data not shown). dCK mRNA and specific activity levels were also measured in MOLT-4 and hypoxanthine-guanine phosphoribosyltransferase-deficient CEM AB9228 $\mathrm{T}$ lymphoblasts and the EBV-immortalized B lymphoblast lines GM558 and MGL-8 (Fig. 6, $B$ and $C$ ). It is apparent that Raji transformed B lymphoblasts have significantly more dCK mRNA and activity than do the EBV-immortalized cells from peripheral blood.

\section{Discussion}

Although it has been shown that thymocytes and T lymphoblasts have high dCK activity in relation to most nonlymphoid tissues 


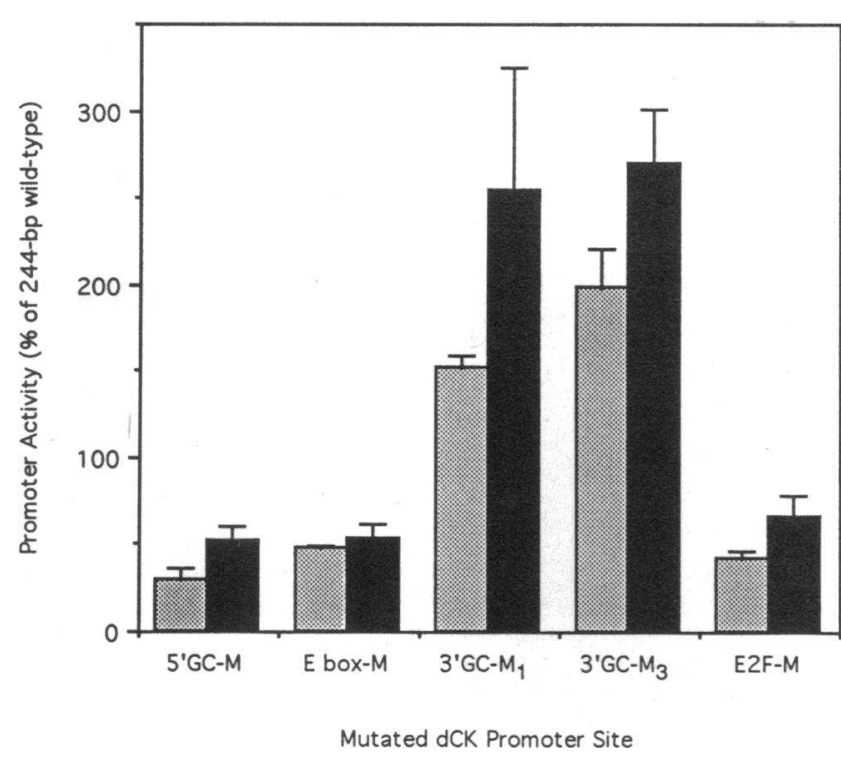

Figure 4. Transfection of site-specific mutant constructs into Jurkat (stippled bars) and Raji (solid bars) cells. The sequence alterations in the mutant constructs are described in Methods. 3'GC-M $\mathbf{M}_{1}$ and 3'GC$\mathrm{M}_{3}$ contain two different mutations at the same site in the dCK promoter CAT activities were normalized to $\beta$-galactosidase activities and are represented as a percentage of the wild-type 244-bp promoter. Bars represent mean $\pm \mathrm{SD}$ of two separate experiments done in duplicate.

$(13,15)$, it was unclear whether $\mathrm{T}$ cells had more activity than B cells. Early studies demonstrated that thymocytes and T lymphoblasts were more sensitive to 2 '-deoxyadenosine and $2^{\prime}$-deoxyguanosine toxicity than B lymphoblasts $(37,38)$. It was postulated that high levels of $\mathrm{dCK}$ activity, coupled with low cytoplasmic 5'-nucleotidase or other catabolic activity, trapped purine deoxyribonucleotides intracellularly (13). The accumulation of these purine deoxyribonucleotides could then result in cytotoxicity by a variety of possible mechanisms, including inhibition of ribonucleotide reductase, DNA nicking and subsequent depletion of nicotinamide adenine dinucleotide, ATP depletion, or inhibition of transmethylation reactions (12). The literature on $\mathrm{T}$ versus $\mathrm{B}$ cell $\mathrm{dCK}$ activity is somewhat contradictory, and interpretation of the results is dependent on a critical examination of how the assays were done and which cells were used. dCK activity is regulated by dCTP, ADP, and other metabolites (4); furthermore, several other enzymes such as cytidine deaminase, $5^{\prime}$-nucleotidase, phosphatases, and thymidine kinase 2 greatly influence product formation (15). Although thymic lymphocytes have high dCK activity, activities in other lymphocyte populations vary. Tonsillar, splenic, and peripheral blood $\mathrm{T}$ and $\mathrm{B}$ lymphocytes in particular have lower dCK activities (39-41). If cultured cell lines are used, malignant transformation and extent of differentiation must be considered in addition to lineage (42).

Our earlier studies demonstrated both 5-10-fold higher levels of dCK mRNA in MOLT-4 and Jurkat T lymphoblasts than in EBV-immortalized B lymphoblasts (16) and many-fold higher levels of CAT activity when the dCK promoter-CAT construct was transfected into Jurkat $T$ as compared with Raji B lymphoblasts (18). The use of the Raji cells in the latter experiments was dictated by their high degree of transfectability. We now believe this difference in $\mathrm{dCK}$ reporter gene activity to be an artifact for the following reasons: $(i)$ all dCK promoter deletion mutants, as well as the promoterless pCAT-Basic vector, expressed much more CAT enzyme in Jurkat than in Raji cells; ( ii) Raji cells have 30-40\% more dCK mRNA than Jurkat cells, as determined by Northern analysis; and (iii) nuclear runon assays demonstrated that transcription of the exon 1 region of the gene is proportional to steady-state mRNA levels in both cell lines. Of note here is the marked disparity between Raji B lymphoblasts and EBV-immortalized B lymphoblasts from normal individuals. The Raji cell line was derived from a Burkitt's lymphoma (43) and has undergone malignant transformation. In contrast, the EBV-infected cells have been immortalized, but are not neoplastic. It is of interest that the Raji B lymphoblasts are akin to $\mathrm{T}$ lymphoblasts in their sensitivity to deoxyadenosine and their ability to accumulate purine deoxyribonucleotides $(42,44)$. Whether or not these features result from differences in dCK expression remains uncertain. These data do emphasize the difficulty in extrapolating from cultured cell lines to normal lymphocytes at different stages of development.

We have analyzed the 700-bp promoter of the dCK gene in detail. Four elements in the dCK promoter appear to be of major importance in mediating gene transcription. The GC boxes centered at -313 ( $5^{\prime}$ GC box) and -210 ( $3^{\prime}$ GC box) bind Spl, and mutation at the $5^{\prime}$ site results in significantly less functional activity. Surprisingly, $\mathrm{Sp} 1$ apparently acts as a repressor at the $3^{\prime} \mathrm{GC}$ box. Review of the sequence immediately $3^{\prime}$ to this site revealed a perfect AP2 consensus sequence, and it is possible that inhibition of Sp1 binding is permissive of AP2 activation. Other examples can be cited in which Sp1 exerts primarily repressor activity. Spl and the stage selector protein (SSP) compete for overlapping sites in the human $\gamma$-globin gene promoter. In fetal erythroid cells, SSP activates the $\gamma$-globin gene promoter, whereas in adult erythroid cells, Sp1 binding is enhanced, preventing SSP from binding and thus reducing expression of the $\gamma$-globin gene (45).

The third promoter element, the $\mathrm{E}$ box centered at -300 , was protected from DNase I digestion in a continuous footprint with the 5' GC box, but protein binding and transcriptional activation are independent of Spl. The bHLH protein binding to this $\mathrm{E}$ box is presumably MLTF/USF, since the anti-USF polyclonal antibody abolished DNA binding. It remains possible that other members of the bHLH family interact with this $\mathrm{E}$ box in vivo, or that MLTF/USF heterodimerizes with other bHLH proteins. MLTF/USF binding and transcriptional activation can be further regulated by methylation of the $\mathrm{E}$ box, with methylation having a negative effect (46). This finding may have particular relevance to $\mathrm{dCK}$, since lack of $\mathrm{dCK}$ gene expression in an cytosine arabinoside-resistant HL- 60 cell line could be partially restored with the demethylating agent 5-azacytidine (47).

The fourth promoter element, the E2F half-site, did not footprint well, and protein binding to this region could be detected only indirectly in a gel-shift assay. Nevertheless, DNase I digestion clearly revealed a hypersensitive site, and mutation within this site decreases promoter activity by $\sim 50 \%$. Although E2F may play a role in basal dCK expression, there is no evidence to support the cell cycle-specific regulation of dCK transcription. Arnér et al. have shown that dCK specific activity is constitutively high and does not increase by more than twofold during the cell cycle using resting and activated peripheral blood lymphocytes or elutriated CEM $\mathrm{T}$ lymphoblasts $(15,48)$. Hengstschläger et al. have measured dCK activity and mRNA in elutriated cells, and in two of four cell lines tested, there was a 10-15-fold increase in dCK activity beginning at the G1/S 


\begin{tabular}{|c|c|c|c|c|c|c|c|c|c|c|}
\hline Nuclear extract: & & & & & & Jurka & & & & \\
\hline Competition: & & & Sp1 & & & $\mathrm{d} M \mathrm{ML}$ & & & Sel & \\
\hline & 0 & 웅 & 음 & ర్ర్ర & 음 & 。ั & : & $\stackrel{x}{\stackrel{x}{2}}$ & ồ & 중 \\
\hline
\end{tabular}

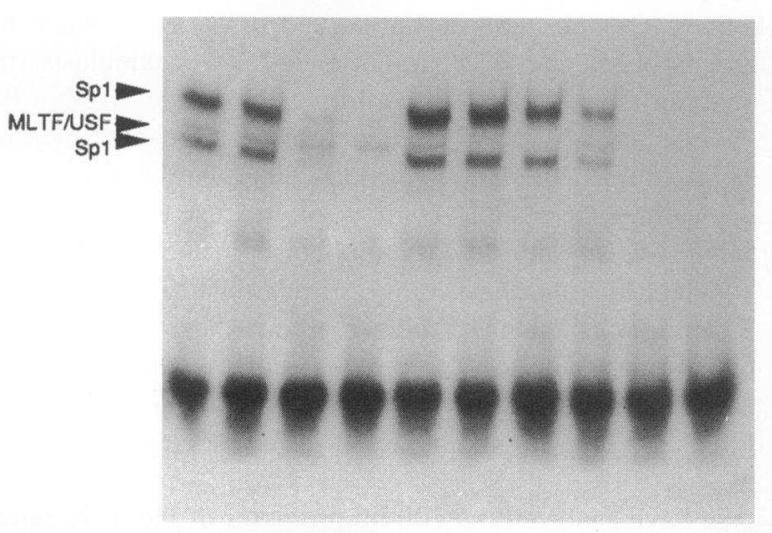

B

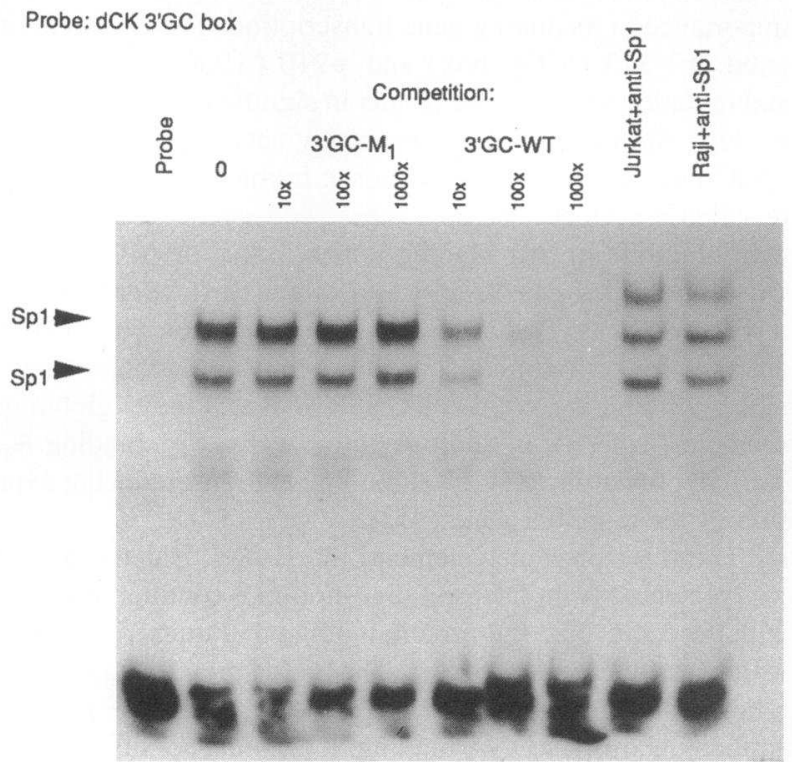

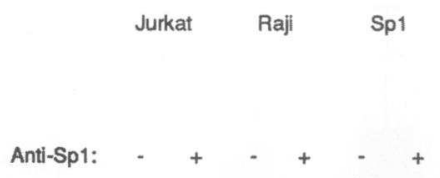

Anti-USF: -++
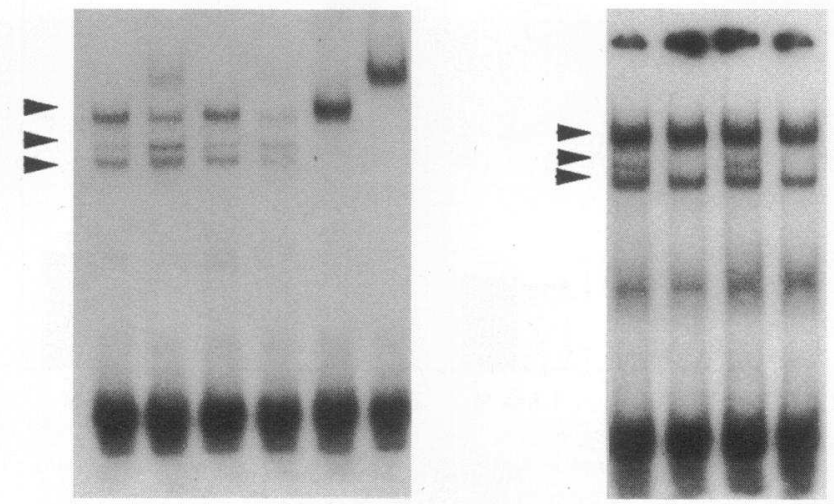

C Probe: E2F-DHFR Nuclear extract: Raji Competition:

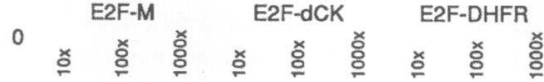

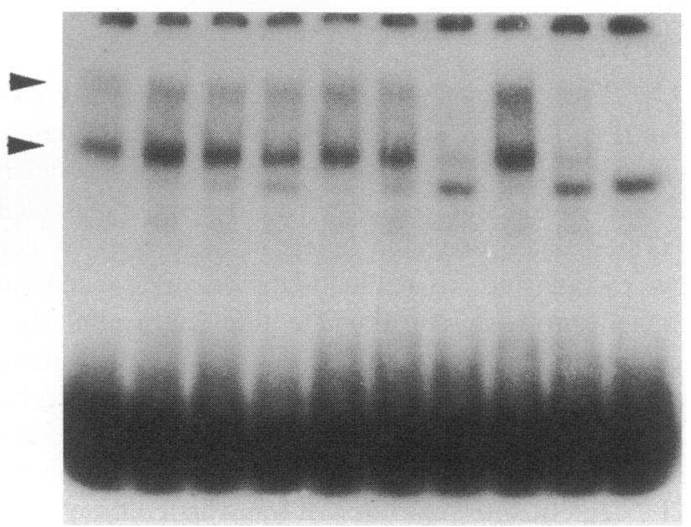

Figure 5. Gel-shift analysis of the 5'GC and E boxes, the 3'GC box, and the E2F site. (A) A single probe containing both the 5'GC and E boxes was incubated with Jurkat or Raji nuclear extract. Where indicated, competitor oligonucleotides had been preincubated with the extract before the addition of probe. The Spl oligonucleotide contains a perfect consensus sequence for Spl; the adenovirus major late promoter (AdMLP) oligonucleotide contains the E box known to bind MLTF/USF. In the middle panel, the 5'GC and E box probe was added to nuclear extract or purified Sp1 ( $2 \mathrm{fpu}$ ) that had been preincubated with or without anti-Spl antibody. In the right panel, the 5'GC and E box probe was used with nuclear extract and anti-USF antibody. Binding reactions were separated on $4 \%$ nondenaturing acrylamide gels, which were then dried and exposed to film for $1-$ 2 d. (B) Analysis of the 3 'GC box. Unless otherwise indicated, Jurkat nuclear extract was used. Competitor oligonucleotides or anti-Spl antibody was used as indicated. $(C)$ Analysis of the E2F site. Binding to the DHFR probe was competed using a mutant E2F site, the dCK E2F half-site, or the DHFR E2F dyad site. With all three probes, identical competition patterns were observed with Jurkat and Raji nuclear extracts.

boundary; however, in none of the four cell lines were there changes in dCK mRNA levels (49). Finally, we have found no difference in steady-state dCK mRNA levels between resting and activated peripheral blood $\mathrm{T}$ cells $(50)$. Thus, $\mathrm{dCK}$ transcription is not cell cycle regulated, despite its functional similarity with the other cell cycle-regulated enzymes that modulate deoxyribonucleotide metabolism, including TK, DHFR, and ribonucleotide reductase.

In contrast to the dCK E2F half-site, the most well-characterized E2F sites in the adenovirus early region 2 (E2), DHFR, $\mathrm{TK}$, and c-myc promoters contain overlapping or nonoverlap- ping dyad sites $(19,20)$. Double mutations of the E2F sites in cellular genes abolish $\mathrm{G} 1 / \mathrm{S}$ regulation either by preventing G1/ $S$ induction $(51-53)$ or by making the promoter constitutively active (54-57). When the DHFR dyad site is mutated to a halfsite, it still binds E2F and is activated by adenovirus E1A or human CMV immediate early proteins $(33,58)$. However, when the human TK promoter is mutated so as to contain only a half-site, it binds E2F poorly, if at all, and G1/S induction is lost (59). In the case of dCK and its half-site, the issue is not so much lack of G1/S induction, but lack of repression during G0. We postulate that the lack of repression during G0 is due 


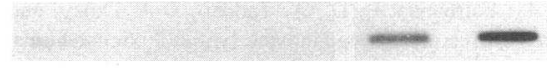

Rajl

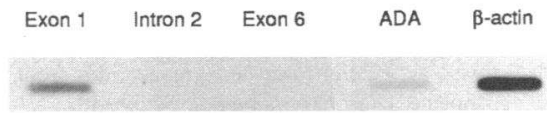

B

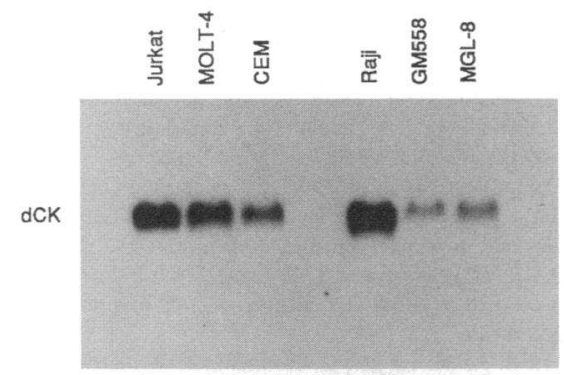

285

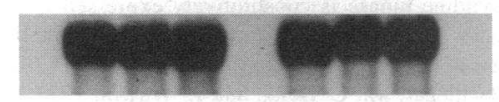

C

specific activity

$\begin{array}{lll}387284229 & 738204209\end{array}$

Figure 6. Endogenous dCK expression in T and B lymphoblast cell lines. $(A)$ Nuclear run-on analysis of dCK transcription in Jurkat and Raji cells. Nuclei were isolated and incubated with $\left[{ }^{32} \mathrm{P}\right]$ UTP for 30 min. Nascent transcripts were purified and subjected to limited hydrolysis with $\mathrm{NaOH}$; equivalent amounts from each cell line were used for hybridization to the blots. Each blot contained $5 \mu \mathrm{g}$ of single-stranded dCK gene fragments in M13 and denatured double-stranded plasmids with ADA and $\beta$-actin cDNAs. After a 2-d hybridization, the blots were briefly washed with $10 \mu \mathrm{g} / \mathrm{ml}$ RNase A. Final washes were in $0.1 \times$ SSC, $0.1 \%$ SDS at $65^{\circ} \mathrm{C}$. Typical autoradiography exposure times were $5 \mathrm{~d}$. (B) Northern blot measuring steady-state dCK mRNA levels in T and B lymphoblast cell lines. Total RNA ( $10 \mu \mathrm{g}$ per lane) was electrophoresed, transferred to nylon, and sequentially hybridized to $\mathrm{dCK}$ cDNA and 28S rRNA oligonucleotide probes. Exposure times for dCK were several hours to overnight and under $60 \mathrm{~min}$ for $28 \mathrm{~S}$. $(C) \mathrm{dCK}$ enzyme activity in the various cell lines, measured using $\mathrm{CdA}$ as a substrate according to Arnér et al. (15).

to the weak binding of E2F repressor complexes to the $\mathrm{dCK}$ half-site, but other members of the E2F family or associated proteins (60) not involved in cell cycle regulation may be important as positive factors for basal dCK promoter function. The question of why dCK and TK, two functionally similar enzymes in the deoxyribonucleoside salvage pathway, diverge in cell cycle expression is an interesting one; the difference may result from the presence of only one E2F half-site in the $\mathrm{dCK}$ promoter.

Although this study has resulted in the delineation of the basic elements regulating $\mathrm{dCK}$ transcription, the mechanism underlying high level thymic gene expression remains obscure. Elucidation of this mechanism will be important, since pharmacologic modulation of $\mathrm{dCK}$ expression could well play a role in enhancing the chemotherapeutic sensitivity of malignant cells to a number of nucleoside analogues. Future studies will be directed at elucidating the role of enhancer elements in dCK tissue-specific expression.

\section{Acknowledgments}

We are indebted to Jane Azizkhan and members of her laboratory (Lineberger Comprehensive Cancer Center, Chapel Hill, NC) for pUC CAT plasmid, nuclear extract, and much advice. Mike Wade was especially helpful in the E2F studies. We would like to thank Peggy Farnham (University of Wisconsin, Madison, WI), Ken Wright, and Jozef Spychala (University of North Carolina, Chapel Hill, NC) for helpful discussions.

This work was supported by National Institutes of Health grant 1-RO1-CA34085.

\section{References}

1. Sarup, J. C., and A. Fridland. 1987. Identification of purine deoxyribonucleoside kinases from human leukemia cells: substrate activation by purine and pyrimidine deoxyribonucleosides. Biochemistry. 26:590-597.

2. Bohman, C., and S. Eriksson. 1988. Deoxycytidine kinase from human leukemic spleen: preparation and characteristics of homogeneous enzyme. Biochemistry. 27:4258-4265.

3. Datta, N. S., D. S. Shewach, M. C. Hurley, B. S. Mitchell, and I. H. Fox. 1989. Human T-lymphoblast deoxycytidine kinase: purification and properties. Biochemistry. 28:114-123.

4. Datta, N. S., D. S. Shewach, B. S. Mitchell, and I. H. Fox. 1989. Kinetic properties and inhibition of human T lymphoblast deoxycytidine kinase. J. Biol. Chem. 264:9359-9364.

5. Kufe, D. W., and D. R. Spriggs. 1985. Biochemical and cellular pharmacology of cytosine arabinoside. Semin. Oncol. 12:34-48.

6. Plunkett, W., S. Chubb, and L. Alexander. 1980. Comparison of the toxicity and metabolism of $9-\beta$-D-arabinofuranosyl-2-fluoroadenine in human lymphoblastoid cells. Cancer Res. 40:2349-2355.

7. Brockman, R. W., Y.-C. Cheng, and R. F. M. Schabel. 1980. Metabolism and chemotherapeutic activity of $9-\beta$-D-arabinofuranosyl-2-fluoroadenine against murine leukemia L1210 and evidence for its phosphorylation by deoxycytidine kinase. Cancer Res. 42:3610-3615.

8. Starnes, M. C., and Y.-C. Cheng. 1987. Cellular metabolism of $2^{\prime}, 3^{\prime}-$ dideoxycytidine, a compound active against human immunodeficiency virus in vitro. J. Biol. Chem. 262:988-991.

9. Carson, D. A., D. B. Wasson, J. Kaye, B. Ullman, D. W. Martin, Jr., R. K. Robins, and J. A. Montgomery. 1980. Deoxycytidine kinase-mediated toxicity of deoxyadenosine analogs toward malignant human lymphoblasts in vitro and toward murine L1210 leukemia in vivo. Proc. Natl. Acad. Sci. USA. 77:6865-6869.

10. Owens, J. K., D. S. Shewach, B. Ullman, and B. S. Mitchell. 1992. Resistance to $1-\beta$-D-arabinofuranosylcytosine in human $\mathrm{T}$-lymphoblasts mediated by mutations within the deoxycytidine kinase gene. Cancer Res. 52:2389-2393.

11. Kawasaki, H., C. J. Carrera, L. D. Piro, A. Saven, T. J. Kipps, and D. A. Carson. 1993. Relationship of deoxycytidine kinase and cytoplasmic 5'-nucleotidase to the chemotherapeutic efficacy of 2-chlorodeoxyadenosine. Blood. 81:597601 .

12. Hershfield, M. S., and B. S. Mitchell. 1995. Immunodeficiency diseases caused by adenosine deaminase deficiency and purine nucleoside phosphorylase deficiency. In The Molecular and Metabolic Basis of Inherited Disease. 7th ed C. R. Scriver, A. L. Beaudet, W. S. Sly, and D. Valle, editors. McGraw-Hill, New York.

13. Carson, D. A., J. Kaye, and J. E. Seegmiller. 1977. Lymphospecific toxicity in adenosine deaminase deficiency and purine nucleoside phosphorylase deficiency: possible role of nucleoside kinase(s). Proc. Natl. Acad. Sci. USA. 74:5677-5681.

14. Osborne, W. R. A. 1986. Nucleoside kinases in T and B lymphoblasts distinguished by autoradiography. Proc. Natl. Acad. Sci. USA. 83:4030-4034.

15. Arnér, E. S. J., T. Spasokoukotskaja, and S. Eriksson. 1992. Selective assays for thymidine kinase 1 and 2 and deoxycytidine kinase and their activities in extracts from human cells and tissues. Biochem. Biophys. Res. Commun. 188:712-718.

16. Chottiner, E. G., D. S. Shewach, N. S. Datta, E. Ashcraft, D. Gribbin, D Ginsburg, I. H. Fox, and B. S. Mitchell. 1991. Cloning and expression of human deoxycytidine kinase. Proc. Natl. Acad. Sci. USA. 88:1531-1535.

17. Spasokoukotskaja, T. E. S. J. Arnér, O. Brosjö, P. Gunvén, G. Juliusson, J. Liliemark, and S. Eriksson. 1995. Expression of deoxycytidine kinase and phosphorylation of 2-chlorodeoxyadenosine in human normal and tumor cells and tissues. Eur. J. Cancer. In press.

18. Song, J. J., S. Walker, E. Chen, E. E. Johnson II, J. Spychala, T. Gribbin, and B. S. Mitchell. 1993. Genomic structure and chromosomal localization of the human deoxycytidine kinase gene. Proc. Natl. Acad. Sci. USA. 90:431-434.

19. Nevins, J. R. 1992. E2F: a link between the Rb tumor suppressor protein and viral oncoproteins. Science (Wash. DC). 258:424-429.

20. Farnham, P. J., J. E. Slansky, and R. Kollmar. 1993. The role of E2F in the mammalian cell cycle. Biochim. Biophys. Acta. 1155:125-131. 
21. Crabb, D. W., C. D. Minth, and J. E. Dixon. 1989. Assaying the reporter gene chloramphenicol acetyltransferase. Methods Enzymol. 168:690-701.

22. Seed, B., and J.-Y. Sheen. 1988. A simple phase-extraction assay for chloramphenicol acetyltransferase activity. Gene. 67:271-277.

23. Eustice, D. C., P. A. Feldman, A. M. Colberg-Poley, R. M. Buckery, and R. H. Neubauer. 1991. A sensitive method for the detection of $\beta$-galactosidase in transfected mammalian cells. BioTechniques. 11:739-742.

24. Dignam, J. D., R. M. Lebovitz, and R. G. Roeder. 1983. Accurate transcription initiation by RNA polymerase II in a soluble extract from isolated mammalian nuclei. Nucleic Acids Res. 11:1475-1489.

25. Blake, M. C., R. C. Jambou, A. G. Swick, J. W. Kahn, and J. C. Azizkhan 1990. Transcriptional initiation is controlled by upstream GC-box interactions in a TATAA-less promoter. Mol. Cell. Biol. 10:6632-6641.

26. Sambrook, J., E. F. Fritsch, and T. Maniatis. 1989. Molecular Cloning: A Laboratory Manual. 2nd ed. Cold Spring Harbor Laboratory Press, Cold Spring Harbor, NY. 6.46-6.48.

27. Kunkel, T. A., J. D. Roberts, and R. A. Zakour. 1987. Rapid and efficient site-specific mutagenesis without phenotypic selection. Methods Enzymol. 154:367-382.

28. Higuchi, R. 1990. Recombinant PCR. In PCR Protocols: A Guide to Methods and Applications. M. A. Innis, D. H. Gelfand, J. J. Sninsky, and T. J. White, editors. Academic Press, Inc. San Diego. 177-183.

29. Blake, M. C., and J. C. Azizkhan. 1989. Transcription factor E2F is required for efficient expression of the hamster dihydrofolate reductase gene in vitro and in vivo. Mol. Cell. Biol. 9:4994-5002.

30. Gumucio, D. L., K. L. Rood, K. L. Blanchard-McQuate, T. A. Gray, A. Saulino, and F. S. Collins. 1991. Interaction of Sp1 with the human $\gamma$ globin promoter: binding and transactivation of normal and mutant promoters. Blood. 78: $1853-1863$

31. Riccio, A., P. V. Pedone, L. R. Lund, T. Olesen, H. S. Olsen, and P. A Andreasen. 1992. Transforming growth factor $\beta 1$-responsive element: closely associated binding sites for USF and CCAAT-binding transcription factor-nuclear factor $\mathrm{I}$ in the type 1 plasminogen activator inhibitor gene. Mol. Cell. Biol. 12:1846-1855.

32. Carthew, R. W., L. A. Chodosh, and P. A. Sharp. 1987. The major late transcription factor binds to and activates the mouse metallothionein I promoter. Genes Dev. 1:973-980.

33. Wade, M., T. F. Kowalik, M. Mudryj, E.-S. Huang, and J. C. Azizkhan 1992. E2F mediates dihydrofolate reductase promoter activation and multiprotein complex formation in human cytomegalovirus infection. Mol. Cell. Biol. 12:43644374.

34. Srivastava, K. K., E. E. Cable, and H. L. Bonkovsky. 1993. Purifying nascent mRNA from nuclear run-on assays using guanidinium isothiocyanate. BioTechniques. 15:226-227.

35. Feinberg, A. P., and B. Vogelstein. 1983. A technique for radiolabeling DNA restriction endonuclease fragments to high specific activity. Anal. Biochem. 132:6-13.

36. Lattier, D. L., J. C. States, J. J. Hutton, and D. A. Wiginton. 1989. Cell type-specific transcriptional regulation of the human adenosine deaminase gene Nucleic Acids Res. 17:1061-1076.

37. Carson, D. A. J. Kaye, and J. E. Seegmiller. 1978. Differential sensitivity of human leukemic $\mathrm{T}$ cell lines and $\mathrm{B}$ cell lines to growth inhibition by deoxyadenosine. J. Immunol. 121:1726-1731.

38. Mitchell, B. S., E. Mejias, P. E. Daddona, and W. N. Kelley. 1978 Purinogenic immunodeficiency diseases: selective toxicity of deoxyribonucleosides for T cells. Proc. Natl. Acad. Sci. USA. 75:5011-5014.

39. Gelfand, E. W., J. J. Lee, and H. M. Dosch. 1979. Selective toxicity of purine deoxynucleosides for human lymphocyte growth and function. Proc. Natl. Acad. Sci. USA. 76:1998-2002.

40. Cohen, A., J. W. W. Lee, H. M. Dosch, and E. W. Gelfand. 1980. The expression of deoxyguanosine toxicity in $\mathrm{T}$ lymphocytes at different stages of maturation. J. Immunol. 125:1578-1582.
41. Fairbanks, L. D., A. Taddeo, J. A. Duley, and H. A. Simmonds. 1990. Mechanisms of deoxyguanosine lymphotoxicity: human thymocytes, but not peripheral blood lymphocytes accumulate deoxy-GTP in conditions simulating purine nucleoside phosphorylase deficiency. J. Immunol. 144:485-491.

42. Goday, A., H. A. Simmonds, G. S. Morris, and L. D. Fairbanks. 1984. B cells as well as $\mathrm{T}$ cells form deoxynucleotides from either deoxyadenosine or deoxyguanosine. Clin. Exp. Immunol. 56:39-48.

43. Pulvertaft, R. J. V. 1964. Cytology of Burkitt's tumour (African lymphoma). Lancet. i:238-240.

44. Carson, D. A., J. Kaye, and D. B. Wasson. 1981. The potential importance of soluble deoxynucleotidase activity in mediating deoxyadenosine toxicity in human lymphoblasts. J. Immunol. 126:348-352.

45. Jane, S. M., D. L. Gumucio, P. A. Ney, J. M. Cunningham, and A. W. Nienhuis. 1993. Methylation-enhanced binding of Spl to the stage selector element of the human $\gamma$-globin gene promoter may regulate developmental specificity of expression. Mol. Cell. Biol. 13:3272-3281.

46. Watt, F., and P. L. Molloy. 1988. Cytosine methylation prevents binding to DNA of a HeLa cell transcription factor required for optimal expression of the adenovirus major late promoter. Genes Dev. 2:1136-1143.

47. Kong, X. B., W. P. Tong, and T. C. Chou. 1991. Induction of deoxycytidine kinase by 5 -azacytidine in an HL60 cell line resistant to arabinosylcytosine. Mol. Pharmacol. 39:250-257.

48. Arnér, E. S. J., M. Flygar, C. Bohman, B. Wallström, and S. Eriksson. 1988. Deoxycytidine kinase is constitutively expressed in human lymphocytes: consequences for compartmentation effects, unscheduled DNA synthesis, and viral replication in resting cells. Exp. Cell Res. 178:335-342.

49. Hengstschläger, M., C. Denk, and E. Wawra. 1993. Cell cycle regulation of deoxycytidine kinase: evidence for post-transcriptional control. FEBS (Fed. Eur. Biochem. Soc.) Lett. 321:237-240.

50. Mitchell, B. S., J. J. Song, E. E. Johnson II, E. Chen, and J. S. Dayton. 1993. Regulation of human deoxycytidine kinase expression. Adv. Enzyme Reg. 33:61-68.

51. Mudryj, M., S. W. Hiebert, and J. R. Nevins. 1990. A role for the adenovirus inducible E2F transcription factor in a proliferation dependent signal transduction pathway. EMBO (Eur. Mol. Biol. Org.) J. 9:2179-2184.

52. Means, A. L., J. E. Slansky, S. L. McMahon, M. W. Knuth, and P. J. Farnham. 1992. The HIP1 binding site is required for growth regulation of the dihydrofolate reductase gene promoter. Mol. Cell. Biol. 12:1054-1063.

53. Slansky, J. E., Y. Li, W. G. Kaelin, and P. J. Farnham. 1993. A protein synthesis-dependent increase in E2F1 mRNA correlates with growth regulation of the dihydrofolate reductase promoter. Mol. Cell. Biol. 13:1610-1618.

54. Dalton, S. 1992. Cell cycle regulation of the human $c d c 2$ gene. EMBO (Eur. Mol. Biol. Org.) J. 11:1797-1804.

55. Kim, Y. K., and A. S. Lee. 1992. Identification of a protein-binding site in the promoter of the human thymidine kinase gene required for the G1-Sregulated transcription. J. Biol. Chem. 267:2723-2727.

56. Fridovich-Keil, J. L., P. J. Markell, J. M. Gudas, and A. B. Pardee. 1993. DNA sequences required for serum-responsive regulation of expression from the mouse thymidine kinase promoter. Cell Growth Differ. 4:679-687.

57. Lam, E. W.-F., and R. J. Watson. 1993. An E2F-binding site mediates cell-cycle regulated repression of mouse B-myb transcription. EMBO (Eur. Mol. Biol. Org.) J. 12:2705-2713.

58. Hiebert, S. W., M. Blake, J. Azizkhan, and J. R. Nevins. 1991. Role of E2F transcription factor in E1A-mediated trans activation of cellular genes. $J$. Virol. 65:3547-3552.

59. Li, L.-J., G. S. Naeve, and A. S. Lee. 1993. Temporal regulation of cyclin A-p107 and p $33^{\text {cak2 }}$ complexes binding to a human thymidine kinase promoter element important for G1-S phase transcriptional regulation. Proc. Natl. Acad. Sci. USA. 90:3554-3558.

60. Chittenden, T., D. M. Livingston, and J. A. DeCaprio. 1993. Cell cycle analysis of E2F in primary human $T$ cells reveals novel E2F complexes and biochemically distinct forms of free E2F. Mol. Cell. Biol. 13:3975-3983. 